\title{
A water-soluble cyclotriveratrylene-based supra-amphiphile: synthesis, pH-responsive self-assembly in water and its application in controlled drug release
}

Danyu Xia,* Yang Li, Kecheng Jie, Bingbing Shi and Yong Yao*

Department of Chemistry, Zhejiang University, Hangzhou, 310027, P. R. China

Fax and Tel: +86-571-8795-3189; Email address: yaoyong@zju.edu.cn, danyuxia@zju.edu.cn

\section{Supporting Information (13 pages)}

1. Materials and Methods $S 2$

2. Synthetic routes for compound 2 and WCTV S3

3. Synthesis of $\mathbf{2}$ and $\mathbf{W C T V} S 3$

$\begin{array}{lll}\text { 4. } & X \text {-ray crystal data of } 2 & S 7\end{array}$

5. Partial 2 D NOESY spectra of an equimolar solution of WCTVدG S7

6. The determination of the association constant of complex WCTV $\supset$ G by Isothermal S8 titration calorimetry (ITC) experiment

7. $p H$-Responsive complexation of $\mathbf{W C T V} \boldsymbol{\top} \mathbf{G} S$

8. Critical aggregation concentration (CAC) determination of $\boldsymbol{G}$ and $\mathbf{W C T V} \boldsymbol{G} \quad S 9$

9. AFM result of the self-assemled vesicles $S 10$

10. Dynamic light scattering (DLS)experiment $S 10$

11. DOX encapsulation experiments $S 10$

12. TEM and DLS results of the DOX-loaded vesicles S11

13. Controllable DOX release in vitro experitment S12

14. Relative cell viabilities $\quad S 12$

References $\quad S 13$ 


\section{Materials and methods}

Compound $\mathbf{1}$ and compound $\mathbf{G}$ were commercially available. All reagents were commercially available and used as supplied without further purification. Solvents were either employed as purchased or dried according to procedures described in the literature. NMR spectra were recorded with a Bruker Avance DMX 600 spectrophotometer or a Bruker Avance DMX 400 spectrophotometer. Low-resolution electrospray ionization mass spectra were recorded with a Bruker Esquire 3000 Plus spectrometer (Bruker-Franzen Analytik GmbH Bremen, Germany) equipped with an ESI interface and an ion trap analyzer. High-resolution mass spectrometry experiments were performed with a Bruker 7-Tesla FT-ICR mass spectrometer equipped with an electrospray source (Billerica, MA, USA). The melting points were collected on a SHPSIC WRS-2 automatic melting point apparatus. Isothermal titration calorimetric (ITC) measurements were performed on a VP-ITC micro-calorimeter (Microcal, USA).The determination of the critical aggregation concentration (CAC) values was carried out on a DDS-307 instrument. Transmission electron microscopy investigations were carried out on a JEM-1200EX instrument. Atomic force microscopy (AFM) experiments were performed on a Multi-Mode Nanoscope-IIIa Scanning Probe Microscope (Veeco Company, USA) in the tapping mode. Dynamic light scattering was carried out on a Malvern Nanosizer $S$ instrument at room temperature. The crystal structures were solved by SHELXS-97 ${ }^{\text {S1 }}$ and refined by SHELXL-97. ${ }^{\text {S2 }}$ UV-vis spectra were taken on a Perkin-Elmer Lambda 35 UV-vis spectrophotometer. The confocal scanning laser microscopy investigations were carried out on a CLSM, Radiance 2100, Bio-Rad instrument. 

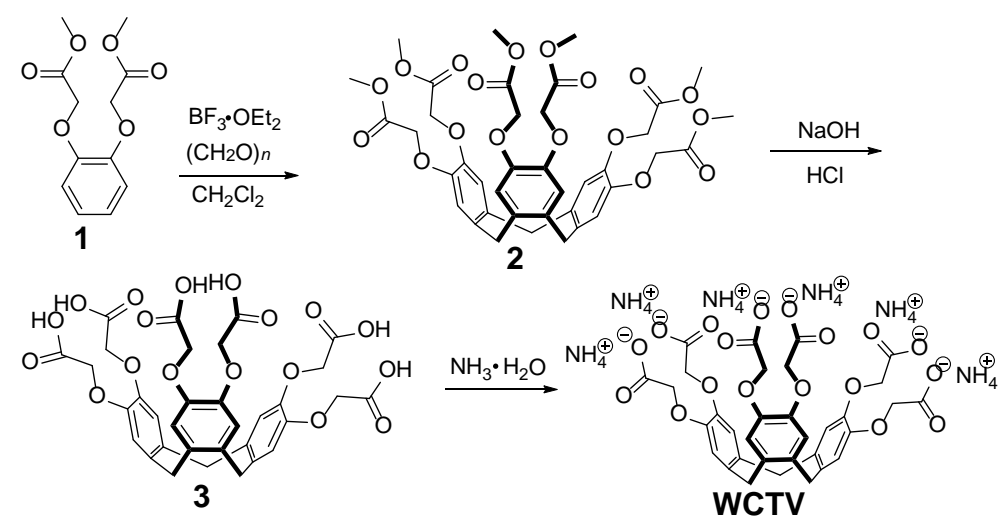

Scheme S1 Synthetic routes for 2 and WCTV.

\section{Synthesis of 2 and $\mathbf{W C T V}$}

\subsection{Synthesis of 2}

To a solution of 1 (2.92 g, $11.5 \mathrm{mmol})$ in dichloromethane (200 mL), paraformaldehyde (0.698 g, 23.0 mmol) was added. Then boron trifluoride diethyl etherate $\left(\mathrm{BF}_{3} \cdot \mathrm{O}\left(\mathrm{C}_{2} \mathrm{H}_{5}\right)_{2}, 1.63 \mathrm{~g}, 11.5 \mathrm{mmol}\right)$ was added to the solution and the mixture was stirred at room temperature for $3 \mathrm{~h}$. Then $200 \mathrm{~mL}$ of methanol was added to the reaction mixture, where product 2 precipitated as a white solid. The product was collected by vacuum filtration and then recrystallized from dichloromethane/methanol mixtures. The white needle-like crystals were dried under high vacuum (1.69 g, 44 \%). Mp 198.5-199.8 ${ }^{\circ} \mathrm{C}$. The proton NMR spectrum of 2 is shown in Figure S1. ${ }^{1} \mathrm{H}$ NMR $\left(400 \mathrm{MHz}, \mathrm{CDCl}_{3}\right.$, room temperature) $\delta(\mathrm{ppm}):{ }^{1} \mathrm{H}$ NMR $(400 \mathrm{MHz}$, $\left.\mathrm{CDCl}_{3}\right) \delta 6.86(\mathrm{~s}, 6 \mathrm{H}), 4.71(\mathrm{~s}, 12 \mathrm{H}), 4.64(\mathrm{~d}, \mathrm{~J}=14 \mathrm{~Hz}, 3 \mathrm{H}), 3.77$ (d, $\left.J=6.0 \mathrm{~Hz}, 18 \mathrm{H}\right), 3.49(\mathrm{~d}, J=14$ $\mathrm{Hz}, 3 \mathrm{H})$. The ${ }^{1} \mathrm{C} \mathrm{C}$ NMR spectrum of 2 is shown in Figure S2. ${ }^{13} \mathrm{C}$ NMR (100 $\mathrm{MHz}, \mathrm{CDCl}_{3}$, room temperature) $\delta(\mathrm{ppm}): 169.74,146.71,133.59,117.66,66.96,52.19,36.19$. LRESIMS is shown in Figure S3: $\mathrm{m} / \mathrm{z} 812.6[\mathrm{M}+\mathrm{Na}]^{+}(100 \%)$. HRESIMS: m/z calcd for $[\mathrm{M}+\mathrm{Na}]^{+} \mathrm{C}_{39} \mathrm{H}_{42} \mathrm{O}_{18} \mathrm{Na}$, 821.2263, found 821.2271, error -1 ppm. 


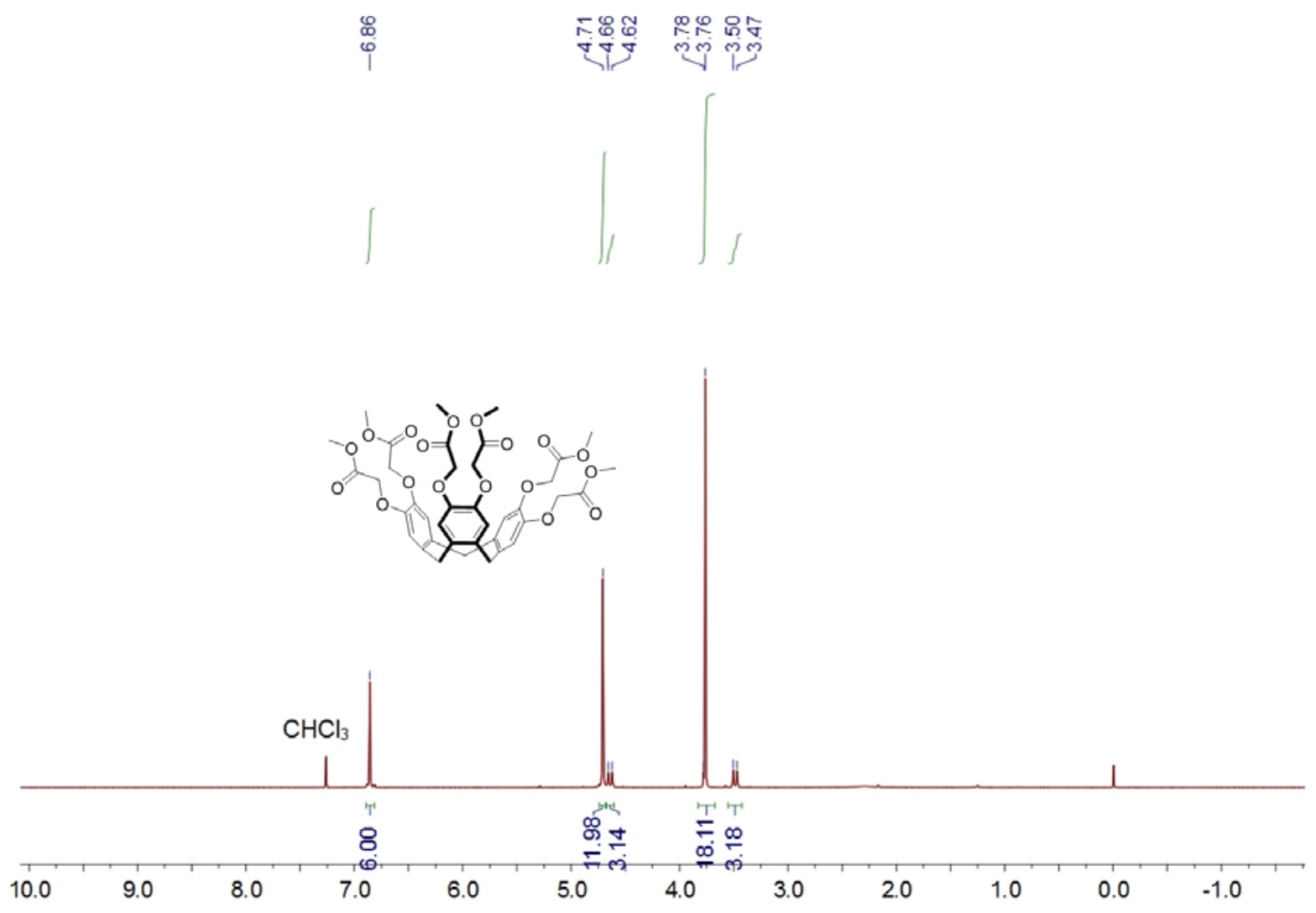

Figure S1. ${ }^{1} \mathrm{H}$ NMR spectrum (400 MHz, $\left.\mathrm{CDCl}_{3}, 293 \mathrm{~K}\right)$ of 2.

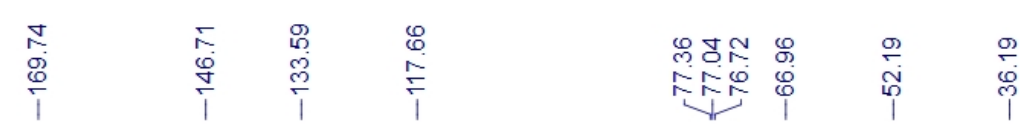

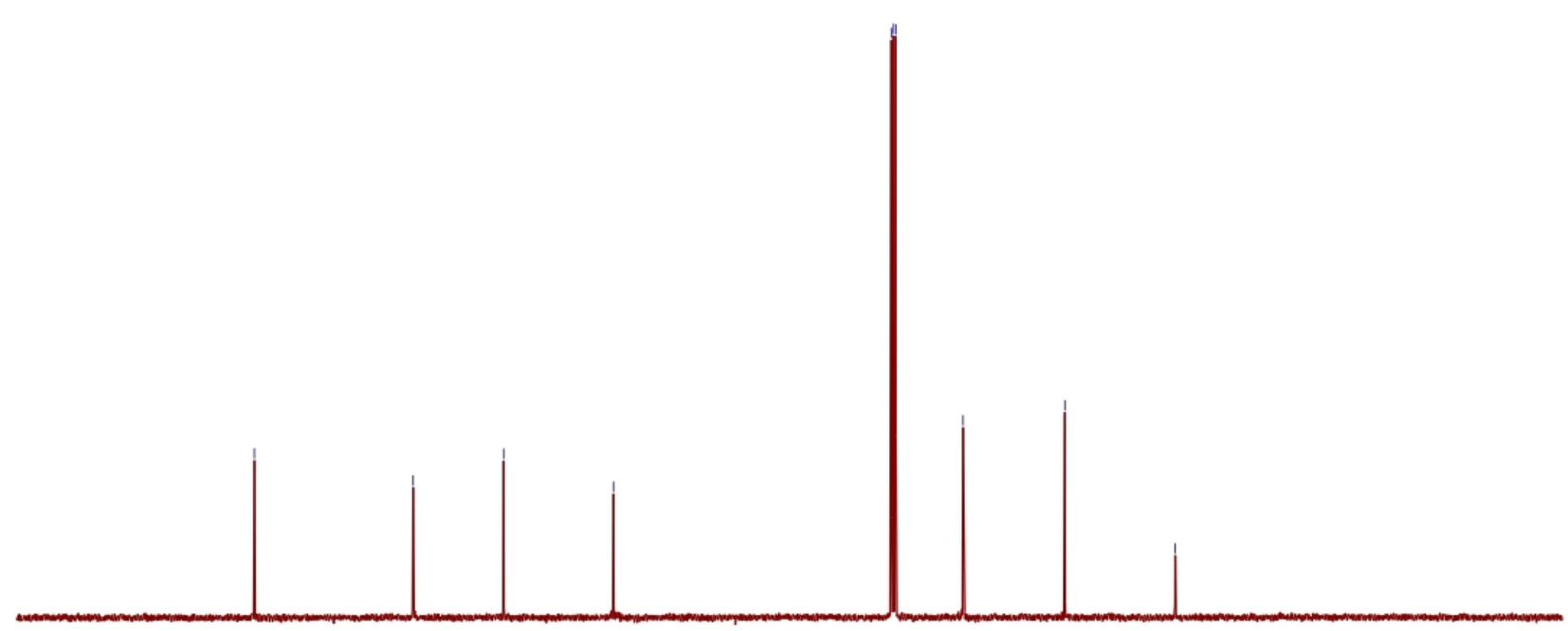




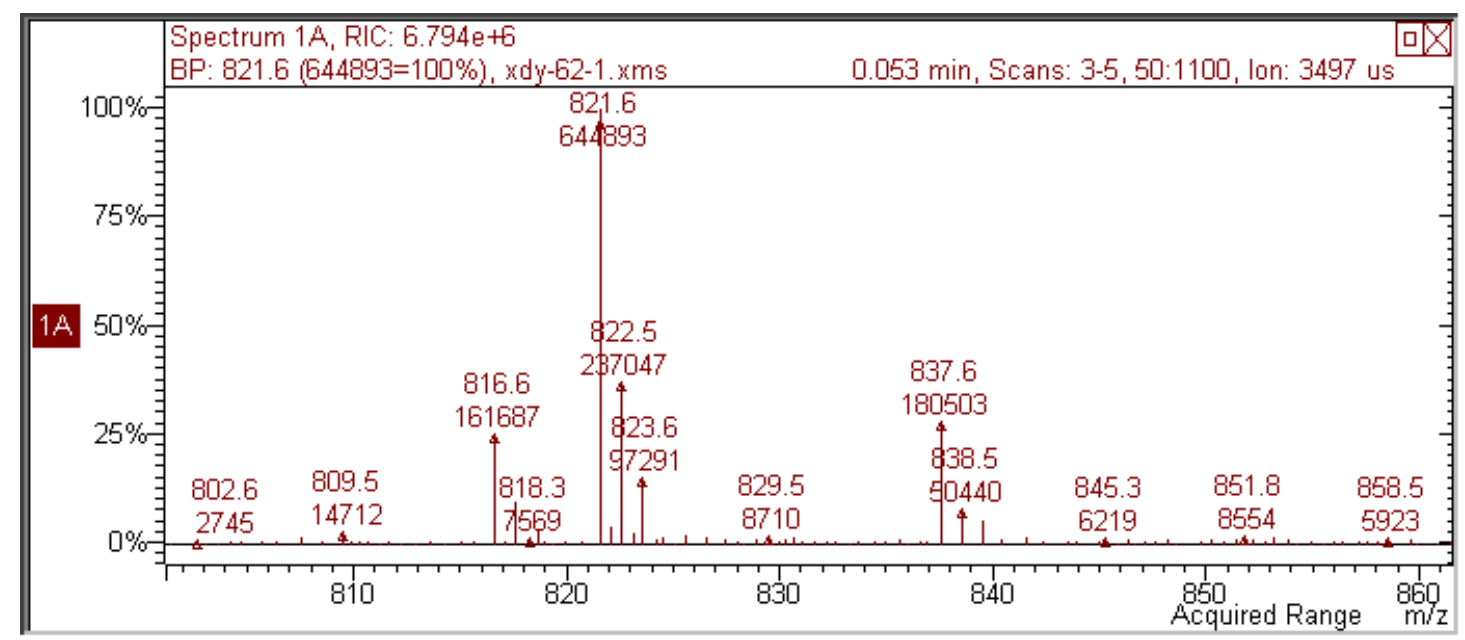

Figure S3. Electrospray ionization mass spectrum of 2. Main peak: $\mathrm{m} / \mathrm{z} 821.6[\mathrm{M}+\mathrm{Na}]^{+}(100 \%)$.

\subsection{Synthesis of WCTV}

A solution of $2(1.20 \mathrm{~g}, 1.50 \mathrm{mmol})$ in enthanol $(120 \mathrm{~mL})$ was treated with $40 \%$ aqueous sodium hydroxide $(120 \mathrm{~mL})$ at reflux for $10 \mathrm{~h}$. The mixture was concentrated under reduced pressure, diluted with water $(30 \mathrm{~mL})$, and acidified with $\mathrm{HCl}$ solution. The precipitated product $\mathbf{3}$ was collected by filtration, washed with water, and dried under vacuum (0.998 g, 93\%). A solution of 3 (0.900 g, 1.25 $\mathrm{mmol})$ and $40 \%$ ammonium hydroxide $(100.0 \mathrm{~mL})$ were stirred at reflux for $5 \mathrm{~h}$. The mixture was concentrated under reduced pressure to get the precipitated product WCTV. Then it was collected by filtration, washed with ethanol and dried under vacuum to obtain WCTV as a white solid (1.03 g, 99\%). Mp: over $250{ }^{\circ} \mathrm{C}$. The proton NMR spectrum of WCTV is shown in Figure. S4. ${ }^{1} \mathrm{H}$ NMR (400 MHz, $\mathrm{D}_{2} \mathrm{O}$, room temperature) $\delta$ (ppm): 6.95 (s, 6H), 4.79 (s, 3H), 4.52 (s, 12H), 3.57 (s, 3H). The ${ }^{13} \mathrm{C}$ NMR spectrum of WCTV is shown in Fig. S2. ${ }^{13} \mathrm{C}$ NMR (100 MHz, $\mathrm{D}_{2} \mathrm{O}$, room temperature) $\delta$ (ppm): 179.37, 148.49, 135.68, 117.11, 70.26, 38.10. LRESIMS is shown in Fig. S3: $\mathrm{m} / \mathrm{z} 713.5\left[\mathrm{M}-6 \mathrm{NH}_{4}+5 \mathrm{H}\right]^{-}$ (100\%). HRESIMS: $\mathrm{m} / \mathrm{z}$ calcd for $\left[\mathrm{M}-2 \mathrm{NH}_{4}-10 \mathrm{NH}_{3}\right]^{2-} \mathrm{C}_{66} \mathrm{H}_{58} \mathrm{O}_{36}, 145.0319$, found 145.0325, error 4 ppm. 


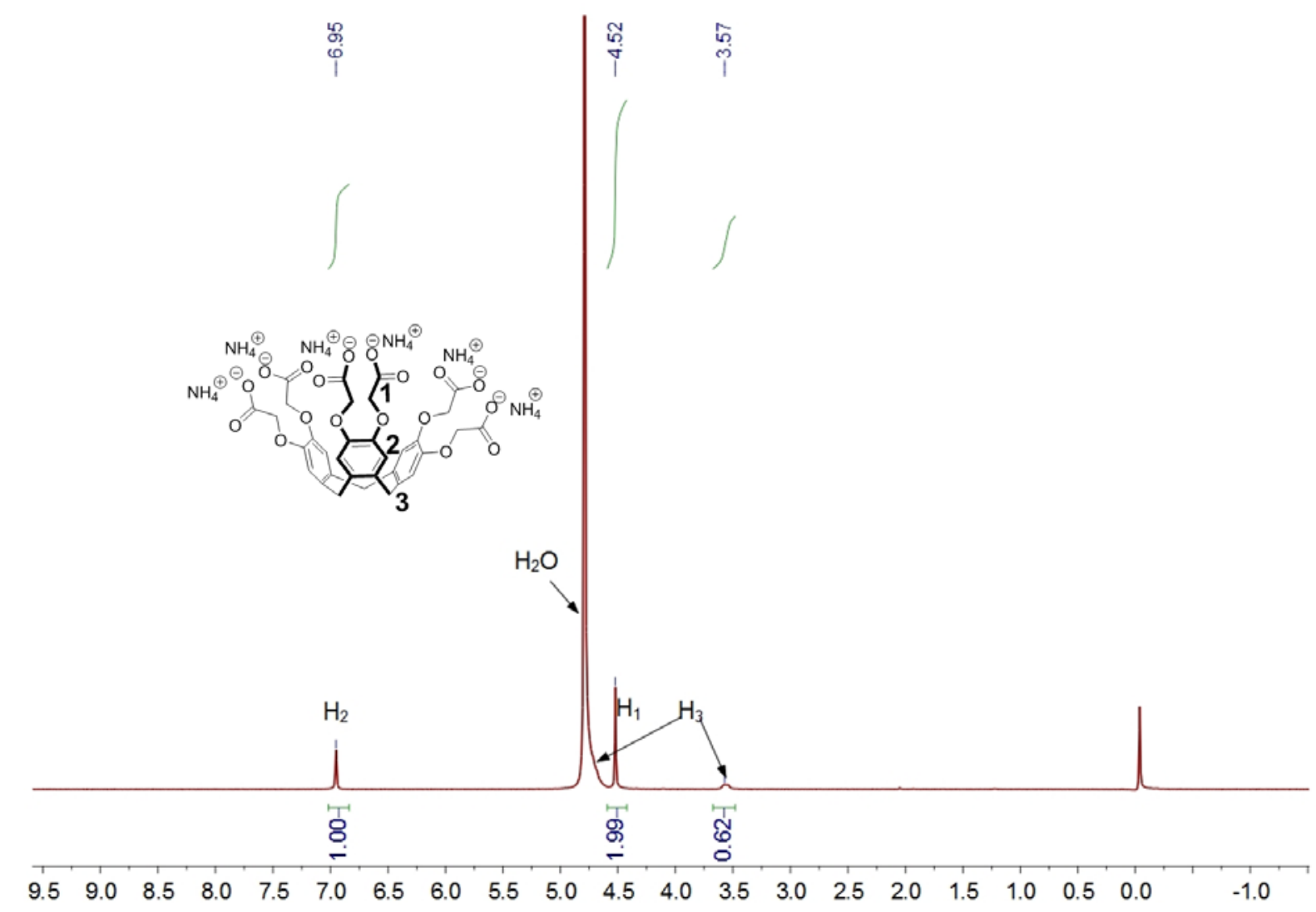

Figure S4. ${ }^{1} \mathrm{H}$ NMR spectrum (400 MHz, $\mathrm{D}_{2} \mathrm{O}$, room temperature) of WCTV.

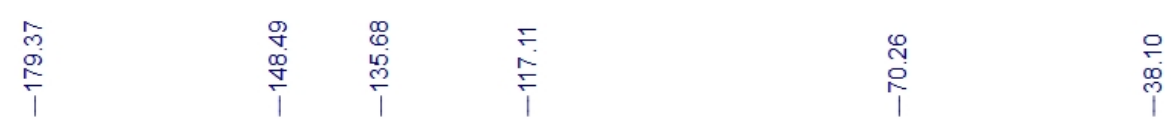

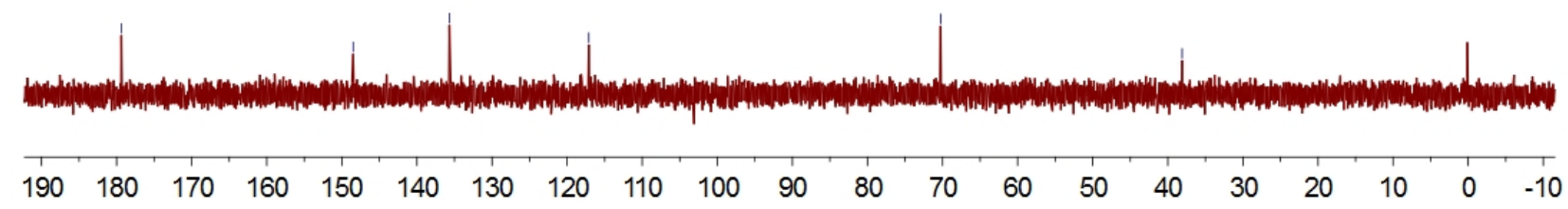

Figure S5. ${ }^{13} \mathrm{C}$ NMR spectrum (100 MHz, $\mathrm{D}_{2} \mathrm{O}$, room temperature) of WCTV. 


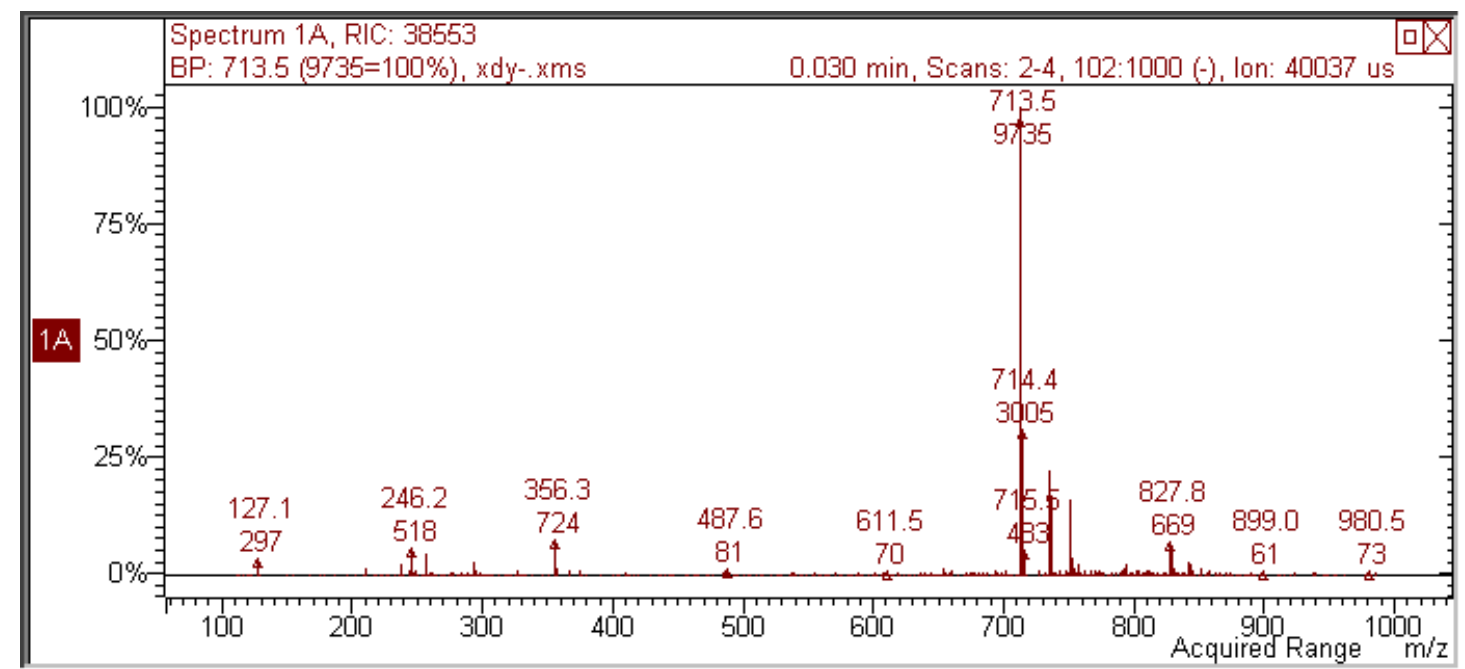

Figure S6. Electrospray ionization mass spectrum of WCTV. Main peak: $\mathrm{m} / \mathrm{z} 821.6\left[\mathrm{M}-6 \mathrm{NH}_{4}+5 \mathrm{H}\right]^{-}$ $(100 \%)$.

\section{X-ray crystal data of 2}

Crystal data of 2: colourless, $\mathrm{C}_{39} \mathrm{H}_{42} \mathrm{O}_{18}, F W 798.73$, monoclinic, space group $C 1_{2} / c 1, a=39.372(2)$, $b=8.0823(2), c=27.4716(14) \AA, \alpha=90.00^{\circ}, \beta=121.374(7)^{\circ}, \gamma=90.00^{\circ}, V=7463.8(6) \AA^{3}, Z=8, D_{\mathrm{c}}=$ $1.422 \mathrm{~g} \mathrm{~cm}^{-3}, T=172 \mathrm{~K}, \mu=0.965 \mathrm{~mm}^{-1}, 27172$ measured reflections, 6583 independent reflections, 540 parameters, 0 restraints, $F(000)=3360.0, R_{1}=0.0617, w R_{2}=0.1431$ (all data), $R_{1}=0.0508, w R_{2}=$ $0.1304[I>2 \sigma(I)]$, max. residual density $0.711 \mathrm{e} \bullet \AA^{-3}$, and goodness-of-fit $\left(F^{2}\right)=1.032$. CCDC-1030157.

\section{Partial 2 D NOESY spectra of an equimolar solution of WCTVدG}

2 D NOESY NMR experiment was employed to study the relative positions of the components in complex WCTV $\supset$ G. NOE correlation signals were observed between protons $\mathrm{H}_{\mathrm{f}}$ on the benzene ring of G and proton $\mathrm{H}_{1}$ and $\mathrm{H}_{3}$ of WCTV (Fig. S7, A and B), between protons $\mathrm{H}_{\mathrm{a}}$ on the benzene ring of $\mathbf{G}$ and proton $\mathrm{H}_{2}$ of WCTV (Fig. S7, C) and between protons $\mathrm{H}_{\mathrm{c}}$ on the benzene ring of $\mathbf{G}$ and proton $\mathrm{H}_{1}$ of WCTV (Fig. S7, D) 


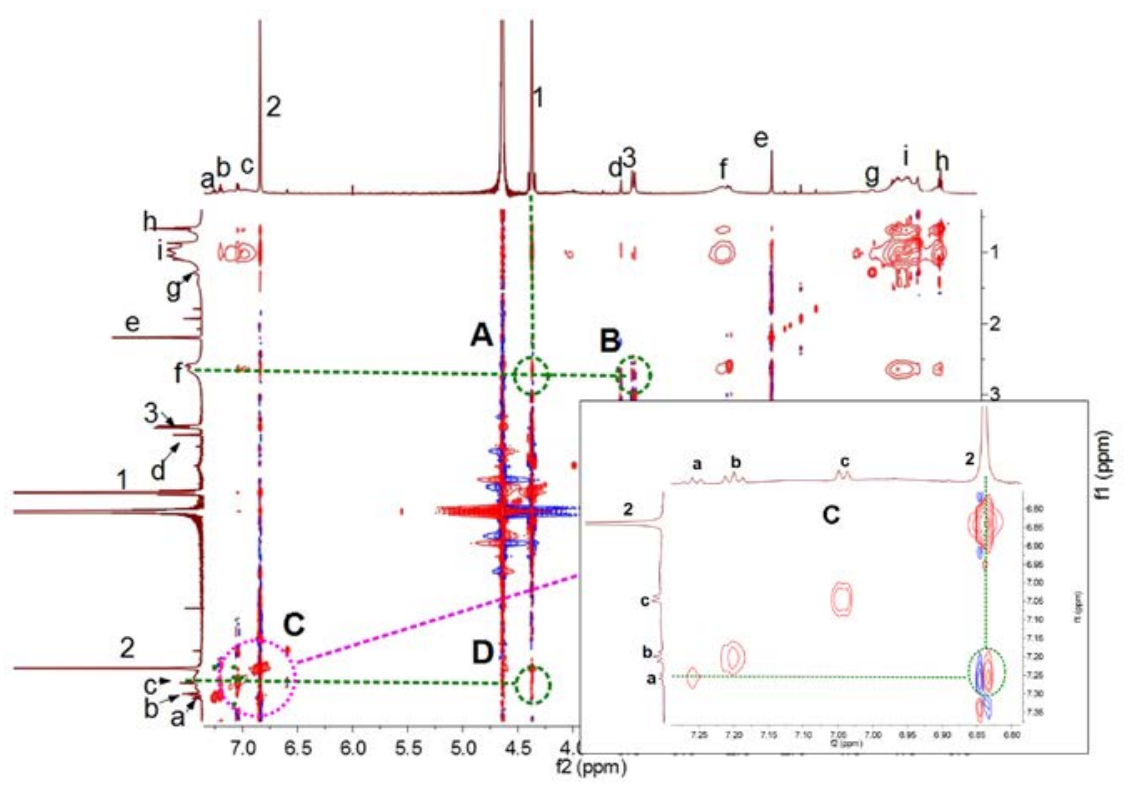

Figure S7. Partial 2D NOESY spectra of an equimolar mixture G and WCTV (2.50 mM) (600 MHz, $\mathrm{D}_{2} \mathrm{O}$, room temperature).

6. The determination of the association constant of complex WCTV $\supset$ G by ITC experiment

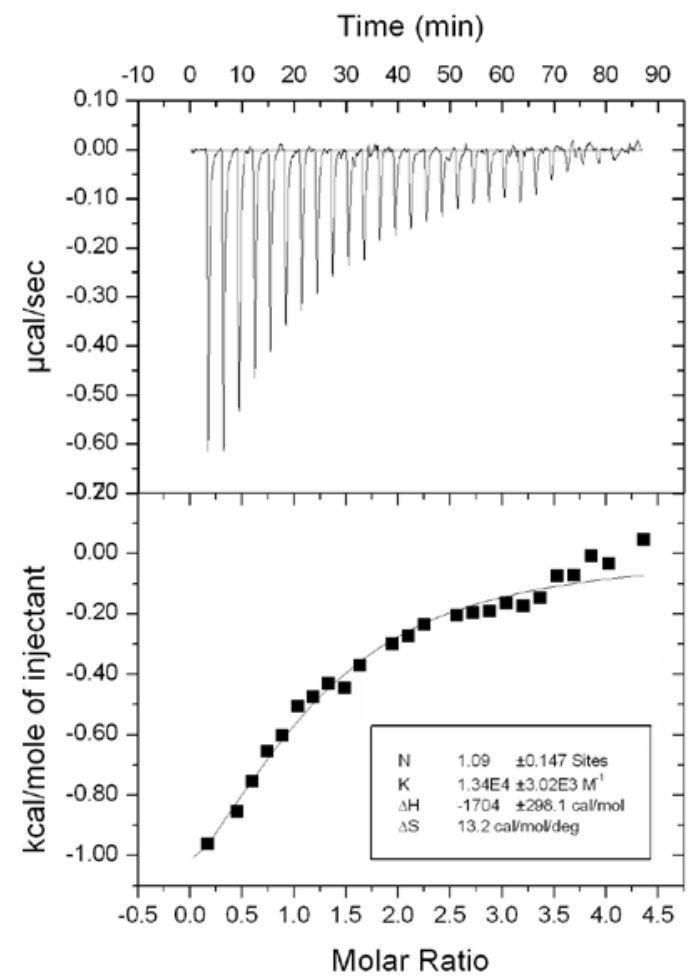

Figure S8. Microcalorimetric titration of WCTV with G in water at 298.15 K. (Top) Raw ITC data for 29 sequential injections (10 $\mu \mathrm{L}$ per injection) of a $\mathbf{G}$ solution $(2.00 \mathrm{mM})$ into a WCTV solution $(0.100 \mathrm{mM})$. (Bottom) Net reaction heat obtained from the integration of the calorimetric traces. 


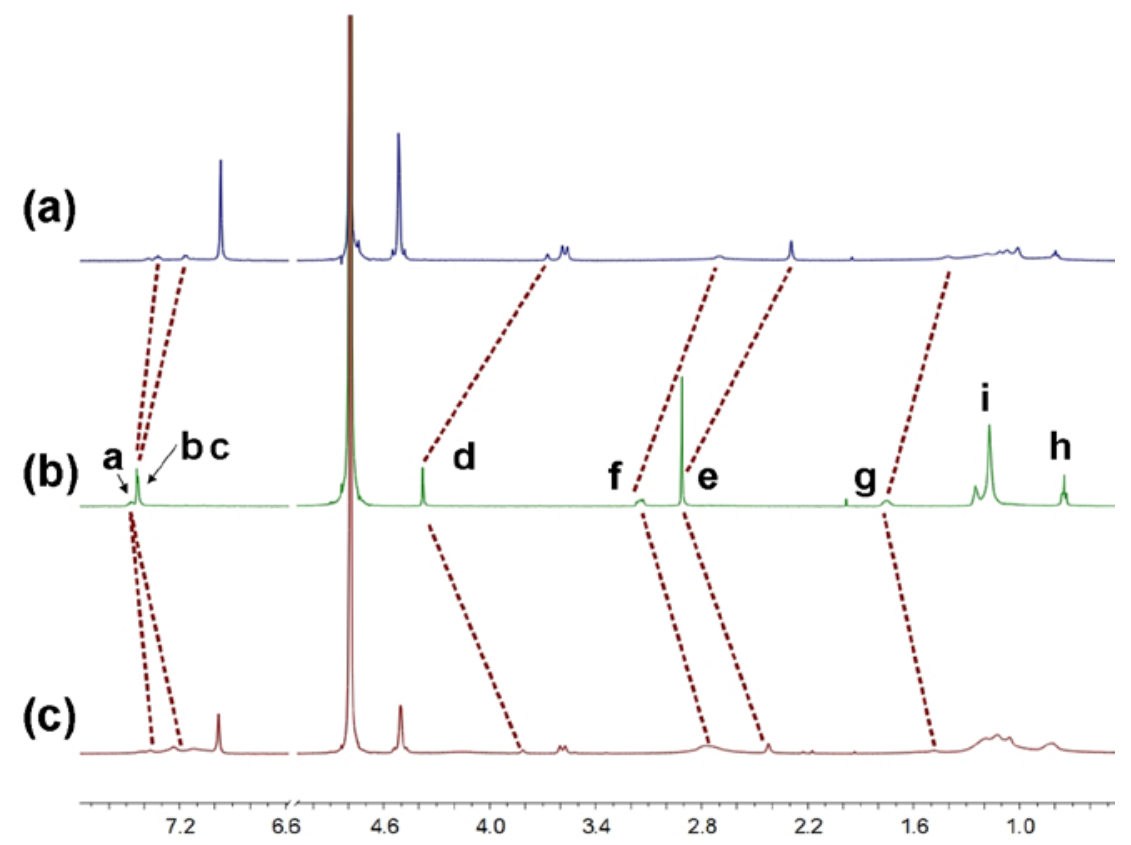

Figure S9. Partial ${ }^{1} \mathrm{H}$ NMR spectra (400 MHz, $\mathrm{D}_{2} \mathrm{O}$, room temperature): (a) WCTVつG (2.50 mM) when the solution $\mathrm{pH}$ was 7.0; (b) WCTVつG (2.50 mM) when the solution $\mathrm{pH}$ decreased to below 7; (c) WCTVつG (2.50 mM) when the solution $\mathrm{pH}$ recovered to 7.0.

8. Critical aggregation concentration (CAC) determination of $\mathbf{G}$ and $\mathbf{W C T V} \supset \boldsymbol{G}$
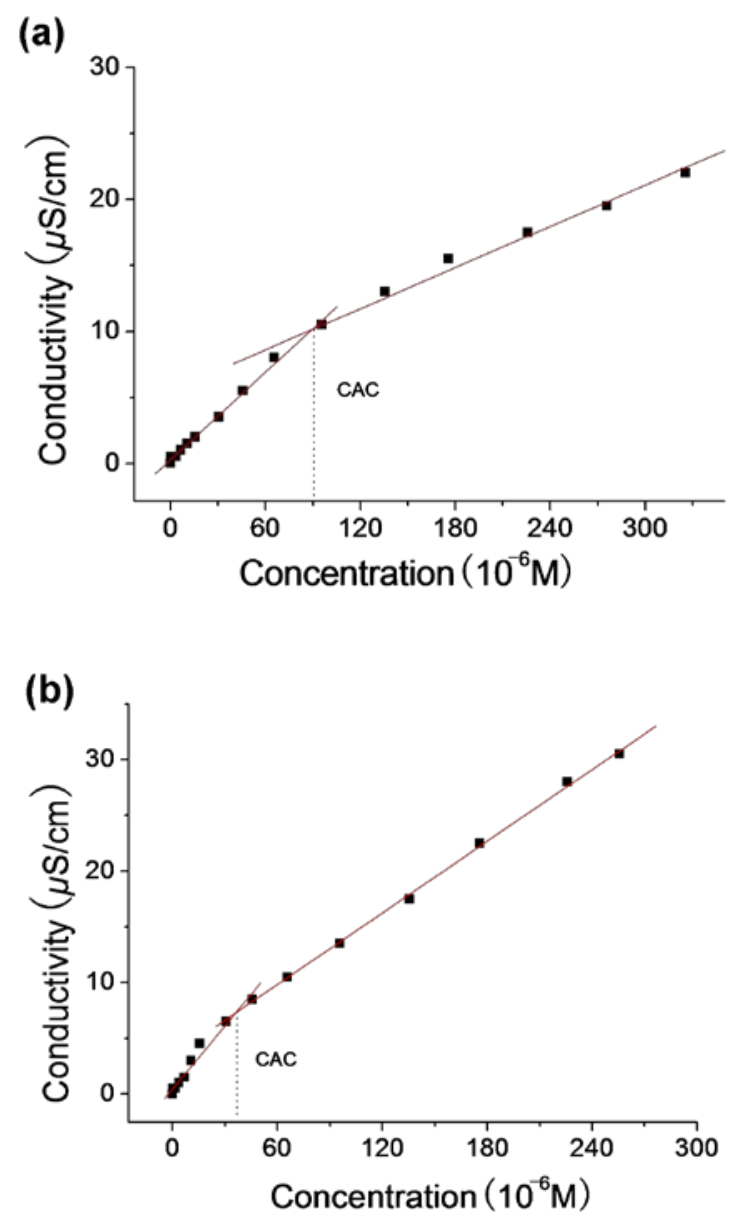
Figure S10. (a) The concentration-dependent conductivity of G. The critical aggregation concentration (CAC) was determined to be $8.98 \times 10^{-5} \mathrm{M}$ and (b) The concentration-dependent conductivity of the mixture of $\mathbf{G}$ and WCTV. The critical aggregation concentration (CAC) was determined to be $3.63 \times$ $10^{-5} \mathrm{M}$.

9. AFM result of the self-assemled vesicles

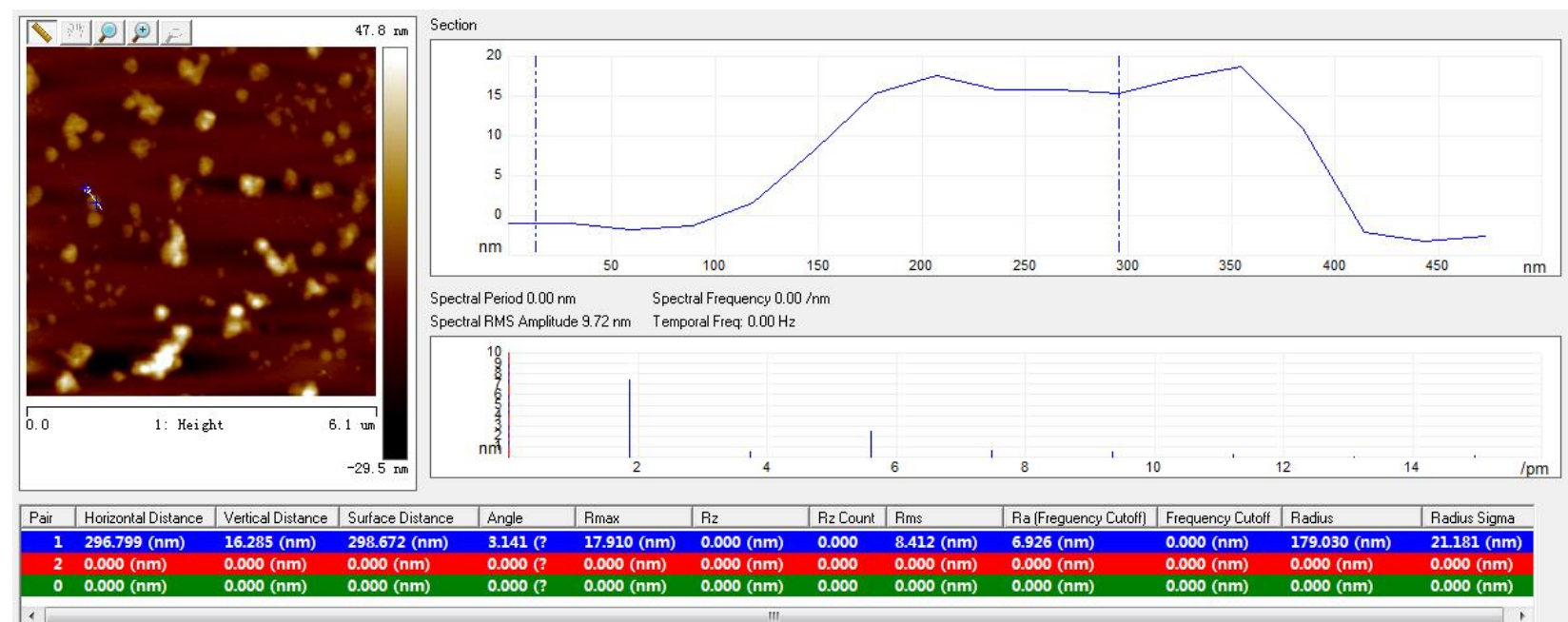

Figure S11. (a) AFM result of the self-assembled vesicles. The height measured from the AFM experiment is the height of two walls of the vesicles. It means that the wall thickness of the vesicles is $8.145 \mathrm{~nm}$.

10. Dynamic light scattering (DLS)experiments
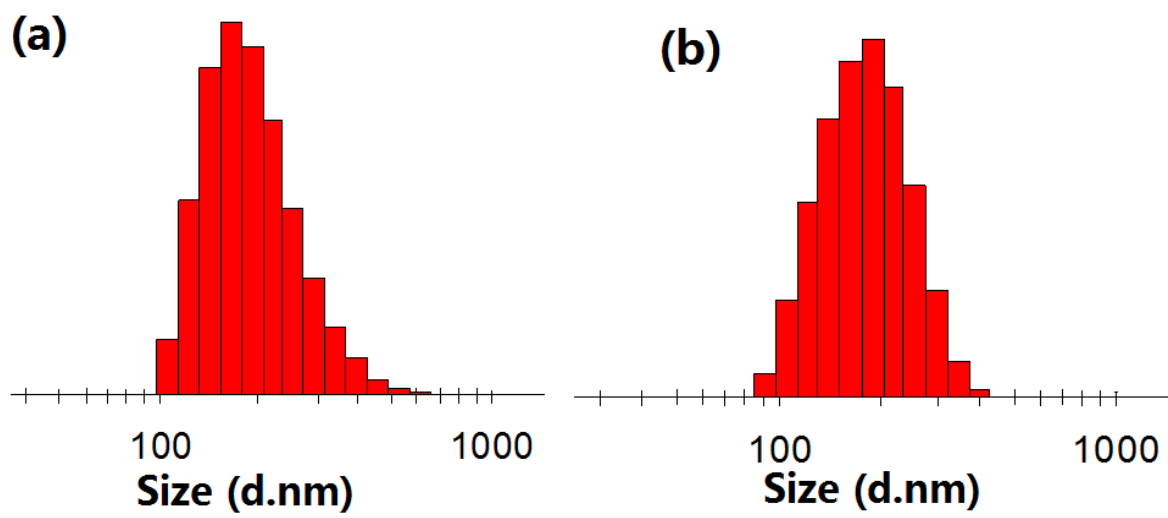

Figure S12. (a) DLS result of WCTV $\supset \mathbf{G}$ aggregates $\left(2.50 \times 10^{-4} \mathrm{M}\right.$ for both $)$ in water; (b) DLS result of the reformed $\mathbf{W C T V} \supset \mathbf{G}$ aggregates $\left(2.50 \times 10^{-4} \mathrm{M}\right.$ for both $)$ in water.

11. DOX encapsulation experiment 
DOX loading experiment: DOX-loaded vesicles were prepared by adding a certain amount of DOX into a freshly prepared aqueous solution of WCTV and $\mathbf{G}\left(2.5 \times 10^{-4} \mathrm{M}\right.$ for both). The ultimate concentrations of DOX, WCTV, and G were 0.05, 0.25, and $0.25 \mathrm{mM}$, respectively. And then the prepared DOX-loaded vesicles were purified by dialysis (molecular weight cutoff $=3500$ ) in distilled water for several times until the water outside the dialysis tube exhibited negligible DOX fluorescence. As a result, DOX was successfully loaded into the vesicles constructed from WCTV $\supset$ G-based supra-amphiphiles. The DOX encapsulation and loading efficiency were calculated by the following equations: ${ }^{\text {S3 }}$

Encapsulation Efficiency $(\%)=\left(m_{\text {DOX-loaded }} / m_{\text {DOX }}\right) 100$ mDOX-loaded and mDOX are mass of DOX encapsulated in vesicles and mass of DOX added, respectively. The mass of DOX was measured by a UV spectrophotometer at $490 \mathrm{~nm}$ and calculated as relative to a standard calibration curve in the concentrations from from $5.00 \times 10^{-3}$ to $2.50 \times 10^{-2} \mathrm{mM}$ in water.

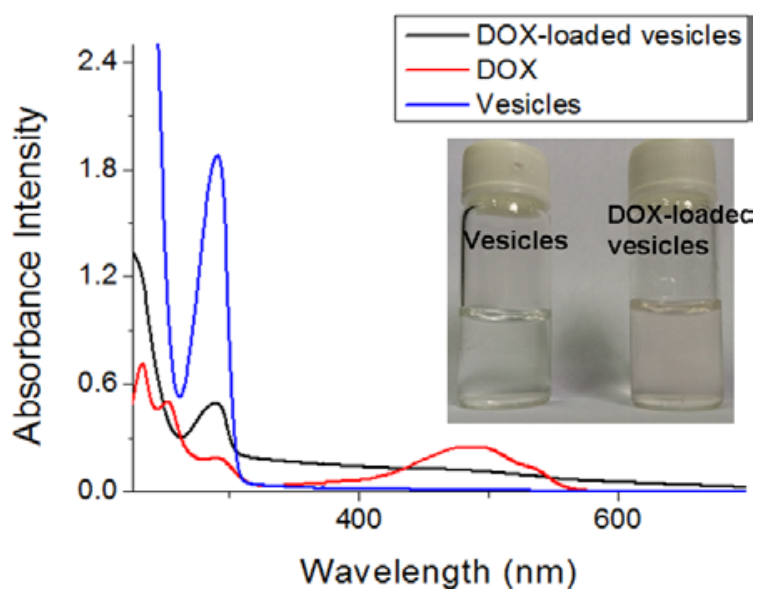

Figure S13. UV-vis absorption spectra of DOX-loaded vesicles, DOX, unloaded vesicles in water. Inset: color change of DOX-loaded vesicle (right) compared with unloaded one (left)

12.TEM and DLS results of the DOX-loaded vesicles

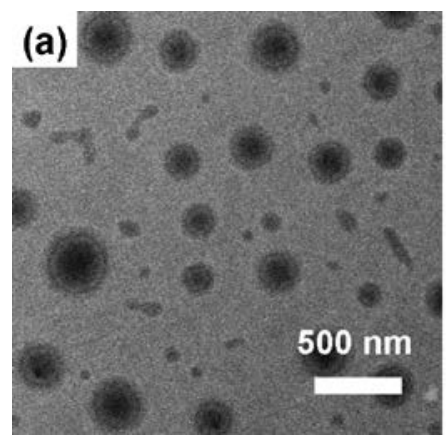

(b)

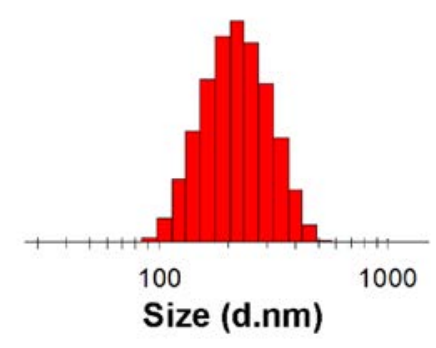

Figure S14. (a)TEM image of DOX-loaded vesicles; (b) DLS results of DOX-loaded vesicles in water 


\section{Controllable DOX release in vitro experiment}

Controllable DOX release: $0.05 \mathrm{M}$ tris- $\mathrm{HCl}(\mathrm{pH}=7.4), 0.2 \mathrm{M}$ sodium acetate $(\mathrm{pH}=4.0)$, and $0.1 \mathrm{M}$ citrate $(\mathrm{pH}=6.5)$ buffer solutions were used as drug release media to simulate normal physiological conditions and the intracellular conditions of tumor. In a typical release experiment, $1.60 \mathrm{~mL}$ of DOX-loaded vesicles were added into $8.40 \mathrm{~mL}$ of appropriate release medium at $37^{\circ} \mathrm{C}$. At selected time intervals, $3 \mathrm{~mL}$ of the release media was taken out for measuring the released DOX concentrations by the UV-vis absorption technique and then was returned to the original release media. The concentration of DOX was determined by measurement of absorbance at $490 \mathrm{~nm}$ using a standard absorbance verses concentration curve constructed for DOX in the corresponding release buffer. By presenting the vesicles to very low $\mathrm{pH}$ (the solution of $\mathrm{HCl}, \mathrm{pH}=2.0$ ), a nearly 100\% release of DOX from DOX-loaded vesicles could be obtained.

\section{Relative cell viabilities}
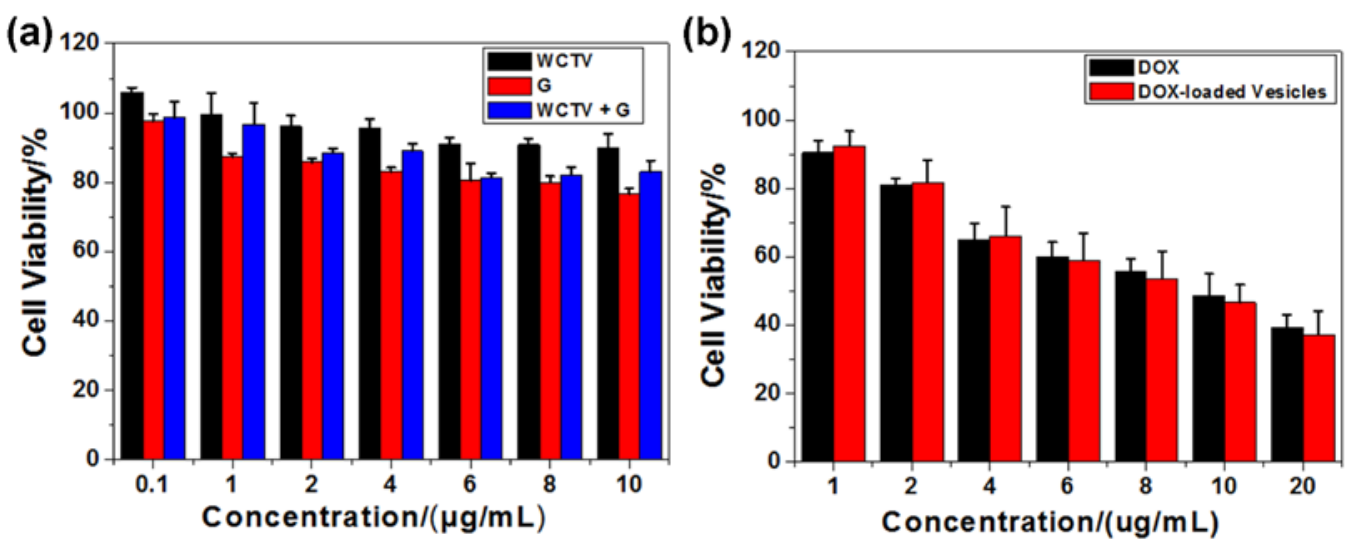

Figure S15. Relative cell viabilities of (a) HepG2 cells (24 h) incubated with WCTV, G, and WCTV + G, respectively, at different concentrations; (b) HepG2 cells (24 h) incubated with DOX and DOX-loaded vesicles at different concentrations. The half-maximal inhibitory concentration ( IC $\left._{50}\right)$ of $\mathbf{G}, \mathbf{W C T V}+\mathrm{G}$, DOX and DOX-loaded vesicles are about $77.88 \mu \mathrm{g} / \mathrm{mL}, 26.37 \mu \mathrm{g} / \mathrm{mL}, 35.70 \mu \mathrm{g} / \mathrm{mL}, 9.553 \mu \mathrm{g} / \mathrm{mL}$ and $9.185 \mu \mathrm{g} / \mathrm{mL}$, respectively. 
References:

S1. Sheldrick, G. M.; SHELXS-97, Program for solution of crystal structures, University of Göttingen, Germany, 1990.

S2. Sheldrick, G. M.; SHELXS-97, Program for refinement of crystal structures, University of Göttingen, Germany, 1997.

S3. Wang, K.; Guo, D.-S.; Wang, X.; Liu, Y. ACS Nano 2011, 5, 2880-2894. 